\title{
A S-band Printed Quadrifilar Helical Antenna for Communication Devices
}

\author{
Xiaozhong Shui \\ School of Information and Electronic Engineering \\ Beijing Institute of Technology \\ Beijing,China \\ shuixiaozhong@163.com
}

\author{
Haibo Tang \\ School of Information and Electronic Engineering \\ Beijing Institute of Technology \\ Beijing,China \\ seafish789@163.com
}

\begin{abstract}
It was mainly analysed a S-band printed quadrifilar helical antenna for communication devices in this paper. And a dielectric loaded wide beam printed quadrifilar helical antenna was designed. A two-stage isolation resistor was placed in wilkinson power divider. The simulation results of this antenna agree well with the measured results.According to the simulation results and measured results,the antenna had a good heart-shaped radiation pattern from $3.05 \mathrm{GHz}$ to $3.45 \mathrm{GHz}$, $3 \mathrm{~dB}$ power-width was more than $160^{\circ}$, the gain was greater than -2dB in the azimuth range, the axial ratio was lower than $5 \mathrm{~dB}$, and the VSWR was lower than 1.4. this printed quadrifilar helical antenna had good electromechanical characteristics,and low cost.
\end{abstract}

Keywords-printed quadrifilar helical antenna; wide beam; wilkinson power divider

\section{INTRODUCTION}

In recent years, due to the easy processing and good performance of quadrifilar helical antenna, it has gain more and more attention, Kilgus first put forward and analyzed the resonant four arms helical antenna performance [1]. It is widely used in satellite communications, microwave transmission, car phone and global positioning system. When car driving on the bumpy road, in order to ensure stable communication, antenna itself should be circular polarization, and Beam width should as far as possible wide. The main form of wide beam circular polarization antenna is chamfer microstrip antenna, resonant four arms helical antenna and cross dipole antenna [2]. Resonant four arms helical antenna can produce a good circular polarization and wide beam heart-shaped pattern [3].

The traditional four arms helical antenna is made by copper wire, because of the complicated machining processes,it is hard to ensure antenna performance, the traditional four arms helical antenna often use coaxial slot balun, the bandwidth is very narrow [4]-[7]. Based on the advanced dielectric substrate processing technology, which advantage is small tolerance, low cost, small volume and good consistency, namely the helical arms can be printed on the soft base plate [8]-[9]. Back feed method use a $3 \mathrm{~dB}$ microstrip form of Wilkinson power divider, the broadband effect is good. dielectric loaded quadrifilar helical antenna has the characteristics of miniaturization.

\section{ANTENNA ANALYSIS AND DESIGN}

A typical structure of the four arms helical antenna is shown in Fig.1.

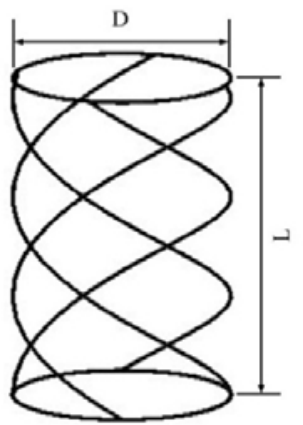

Fig 1. Four arms helical antenna

The Antenna is composed of four helical arms. The length of each helical arm is a quarter wavelength multiplying an integer( $\mathrm{M} \lambda / 4, \mathrm{M}$ is an integer $)$.Each helical arm has equal feeding current magnitude, and the feeding current phase is respective $0^{\circ}, 90^{\circ}, 180^{\circ}, 270^{\circ}$, having $90^{\circ}$ phase difference successively. This kind of rotary feed is better for antenna circular polarization axis ratio. Feed network function is to meet the requirements of equal power allocation and realize phase shift. The parameters of the antenna structure are determined by formula(1):

$$
\mathrm{L}=\sqrt{(L O-k D)^{2}-\pi^{2} D^{2} N^{2}}
$$

In formula(1), $\mathrm{L}$ is the axial height of the helic, Lo is the length of the helical arms, $\mathrm{D}$ is the diameter of the helic, and $\mathrm{N}$ is the number of turns of helic. $\mathrm{k}=1$ ( $\mathrm{N}$ is odd), and $\mathrm{k}=2$ ( $\mathrm{N}$ is even). Parameters of helical such as antenna input impedance, gain, directivity, and axis ratio are mainly determined by the diameter $\mathrm{D}$ of the antenna, the pitch and number of turns. When the $\mathrm{D} / \lambda=0.25 \sim 0.46$, the helical antenna has maximum radiation in one direction of the axis. When $\mathrm{D} / \lambda>0.46$, we will get a conical pattern.

In this paper, the antenna structure is shown in Fig.2. 


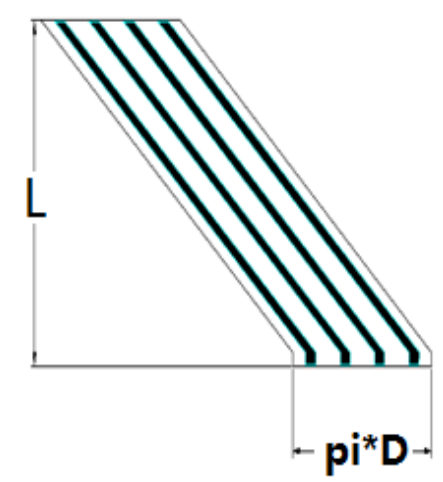

(a)

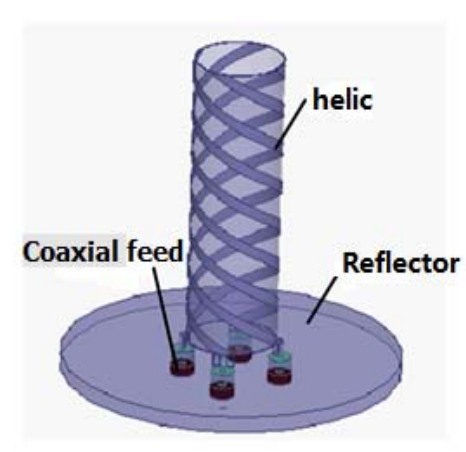

(b)

Fig 2. Four arms helical antenna structure (a) expansion form of four $\operatorname{arms}(\mathrm{b})$ solid structure

The four arms are remaining copper strips which are obtained by milling a double-sided copper-clad soft dielectric plate, and then twine on the cylindrical dielectric column. Above these constitute the basic radiation body of the antenna. In order to form a right-handed circularly polarized radiation wave, helical line around to the right hand relationship with the maximum radiation direction. Overlook the bottom of the feeding port, the feeding phase is in a clockwise order of $0^{\circ}, 90^{\circ}, 180^{\circ}, 270^{\circ}$.

In order to achieve the above-described port feed form, a two-stage micro-strip Wilkinson power divider is shown in Fig.3. The isolation of traditional micro-strip power divider is very poor, which will lead to deterioration of the performance of the antenna. But we adopt micro-strip Wilkinson power divider with patch isolation resistor, the port isolation could be greatly improved. The antenna overall model is shown in Fig.4.
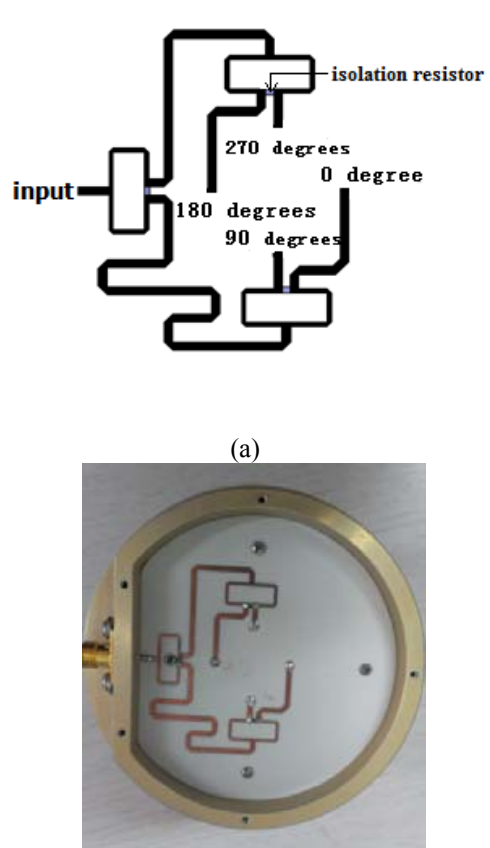

(b)

Fig 3. Wilkinson power divider (a) principle of Wilkinson power divider (b) entity of wilkinson power divider

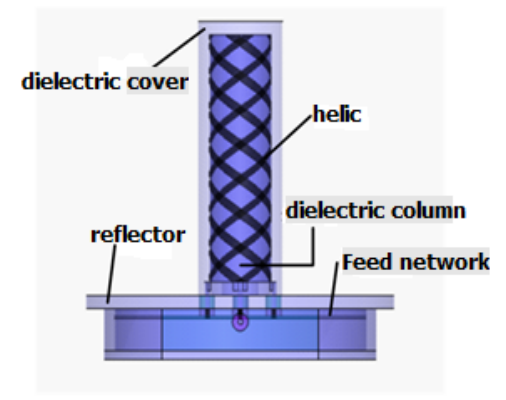

(a)

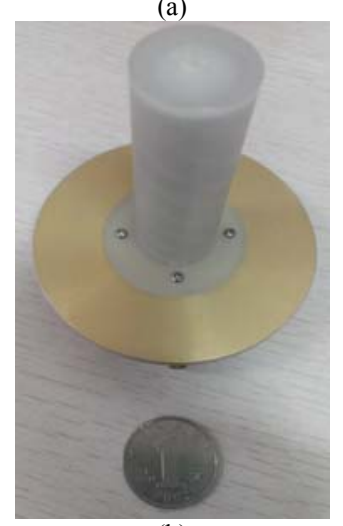

(b)

Fig 4. Antenna entity (a) Antenna overall structure

(b) Antenna entity 
Working frequency band of the antenna is designed in $3.05 \mathrm{GHz}-3.45 \mathrm{GHz}$. The feed network is located in the back cavity. The radiation part adopts mechatronics design concept, taking the stability of the mechanical properties and miniaturization into consideration. We choose rogers 5880 , a thickness of 10 mil. After milling, it is put on the polyethylene pillars, whose relative permittivity is 2.1 . A $3 \mathrm{~mm}$ thick polyethylene outer cover is put outside of the antenna radiation part, the using of polyethylene is equivalent to dielectric loaded, can effectively reduce the size of the antenna. The closed structure ensures the overall mechanical strength of the antenna radiation part, so as to ensure the stability of the electrical properties.

\section{SIMULATION AND MEASURED RESULT}

Table I is the proposed optimal antenna parameters which effect on the performances of the antenna.

TABLE I. ANTENNA PARAMETER

\begin{tabular}{|c|c|c|c|c|}
\hline param & $\mathbf{D}(\mathbf{m m})$ & $\mathbf{L o}(\mathbf{m m})$ & $\boldsymbol{K}$ & $\boldsymbol{N}$ \\
\hline Value & 18.3 & 35 & 2 & 2 \\
\hline
\end{tabular}

The simulation and measured results of VSWR is shown in Fig.5. VSWR is less than 1.4 in frequence band. The simulation results agree well with the measured results.

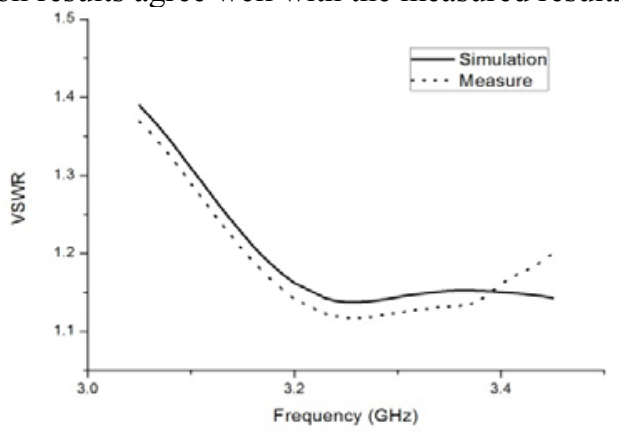

Fig 5. Simulation and measured results of VSWR

The measured result of antenna axis ratio is shown in Fig.6. The results show that as the working frequency increases, the axial ratio becomes smaller. In the entire frequency band, when $\theta$ is between $-90^{\circ}$ and $+90^{\circ}$, the axial ratio is less than $5 \mathrm{~dB}$.

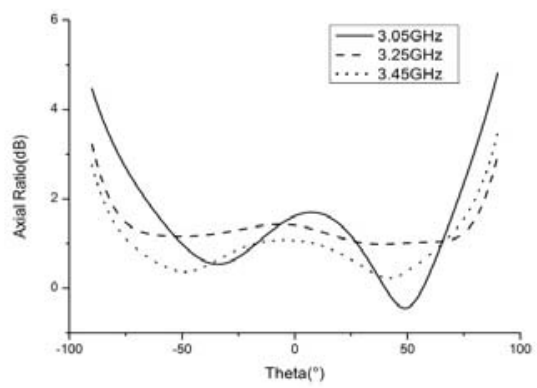

Fig 6. Measured result of axis ratio
The simulation and measured normalized radiation pattern is shown in Fig.7. when antenna is working at the center frequency $3.25 \mathrm{GHz}$. Simulation and measured results agree with each other well. The $3 \mathrm{~dB}$ beam-width reaches $160^{\circ}$, the gain is greater than $-2 \mathrm{~dB}$ in the entire upper half airspace.

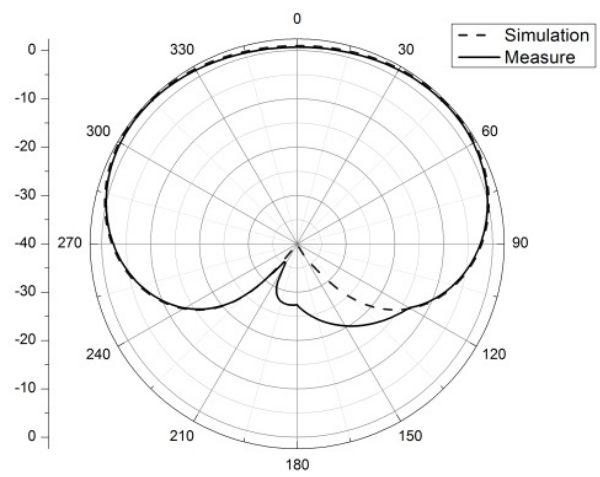

(a) $\varphi=0^{\circ}$

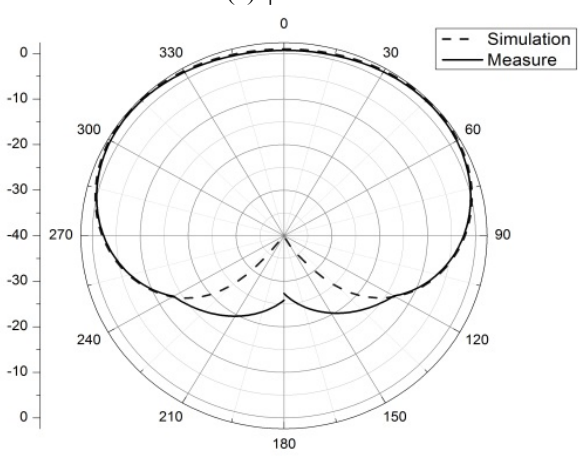

(b) $\varphi=90^{\circ}$

Fig 7. Normalized radiation pattern at $3.25 \mathrm{GHz}$

\section{CONCLUSION}

In this paper, at first we studied the resonant four arm helical antenna, the wide beam printing four arms helical antenna design form was given at $\mathrm{S}$ band., and designed a two-stage Wilkinson power divider, antenna radiation body adopt the new form of totally closed dielectric loaded,which can reduce the size of the antenna,mechanical stability of the structure is good. Simulation and measurement have good consistency. Antenna in-band standing-wave ratio is less than 1.4 , the half power-width was more than $160^{\circ}$, the gain was greater than $-2 \mathrm{~dB}$ in the azimuth range, the axial ratio was lower than $5 \mathrm{~dB}$. Antenna has the outstanding performance, can meet the needs of engineering application.

\section{REFERENCES}

[1] Charles C. Kilgus Resonnat quadrifilar helices[J]. IEEE Transactions on Antennas and Propagation, 1969(17): 349-351.

[2] Charles C. Kilgus Resonnat quadrifilar helix design[J]. Microwave Journal, 1970(18): 49-54 
[3] Charles C.Kilgus. Shaped-Conical Radiation Pattern Performance of the Backfire Quadrifilar Helix[J]. IEEE Transactions on Antennas and Propagation, 1975.5: 392-397.

[4] Robert A.Sainati, Join J.Groppelli, Ralph C.Olesen, Andrew J.Stanland. A Band-Switched Resonant Quadrifilar Helix[J]. IEEE Transactions on Antennas and Propagation, 1982.9, AP-30(5):1010-1013.

[5] Waqar A.Shah, Sultan Shoaib, Qamarul Islam, Muhammad Amin Wide Band Side Fed Bifilar Helix Antenna Caged In Passive Quadrifilar Helix Structure[C]. Radio and Wireless Symposium, 2010 IEEE, 2010: 597-600.
[6] Chen Chen, Fang Yang, Chenjiang Guo, Jiadong Xu. Analysis and Design of a satellite-borne wide-beam quardifilar helix antenna[C]. Microwav Coference,2008.APMC 2008.Asia-Pacific, 2008.10:1-4.

[7] M.Hosseini, M.Hakkak, P.Rezaei.Design of a Dual-Band Quadrifilar Helix Antenna[J]. IEEE Antennas and Wireless Propagation Letters, 2005,4: 39-42.

[8] Shiwen Yang, Soon Hie Tan, Yeow Beng Gan, Chun Wee See. Broadband Conical Printed Quadrifilar Helical Antenna with Integrated Feed Network[J]. Microwave and Optical Technology Letters, 2002, 35: 491-493.

[9] Chen Y Y, Wong K L. Low-profile Broadband Printed Quadrifilar Helical Antenna for Broadcasting Satellite Application[J]. Microwave and Optical Technology Letters, 2003, 36: 134-136. 